\title{
Diode laser irradiation increases microtensile bond strength of dentin
}

Rafael Massunari MAENOSONO(a) Odair BIM JÚNIOR(a)

Marco Antonio Húngaro DUARTE(a)

Regina Guenka PALMA-DIBB(b)

Linda WANG(a)

Sérgio Kiyoshi ISHIKIRIAMA(a)

(a) Universidade de São Paulo - USP, Bauru School of Dentistry, Department of Operative Dentistry, Endodontics and Dental Materials, Bauru, SP, Brazil.

(b) Universidade de São Paulo - USP, Ribeirão Preto School of Dentistry, Department of Restorative Dentistry, Ribeirão Preto, SP, Brazil.
Abstract: Laser irradiation after the immediate application of dentin bonding systems (DBSs) and prior to their polymerization has been proposed to increase bond strength. The objective of this study was to evaluate the effect of diode laser irradiation $(\lambda=970 \mathrm{~nm})$ on simplified DBSs through microtensile bond strength tests. Forty healthy human molars were randomly distributed among four groups $(\mathrm{n}=10)$ according to DBSs used [Adper ${ }^{\mathrm{TM}}$ SingleBond 2 (SB) and Adper ${ }^{\mathrm{TM}}$ EasyOne (EO)], and the respective groups were irradiated with a diode laser (SB-L and EO-L). After bonding procedures and composite resin build-ups, teeth were stored in deionized water for 7 days and then sectioned to obtain stick-shaped specimens $\left(1.0 \mathrm{~mm}^{2}\right)$. The microtensile test was performed at $0.5 \mathrm{~mm} / \mathrm{min}$, yielding bond strength values in $\mathrm{MPa}$, which were evaluated by two-way ANOVA followed by Tukey's test $(p<0.05)$ for individual comparisons. For both adhesive systems, diode laser irradiation promoted significant increases in bond strength values (SB: $33.49 \pm 6.77$; SB-L: $43.69 \pm 8.15$; EO: $19.67 \pm 5.86$; EO-L: $29.87 \pm 6.98$ ). These results suggest that diode laser irradiation is a promising technique for achieving better performance of adhesive systems on dentin.

Keywords: Dentin; Lasers; Tensile Strength.

\section{Introduction}

One of the main challenges in adhesive dentistry is obtaining a reliable link between composite restorations and dentin, ${ }^{1}$ especially with the simplified dentin bonding systems (DBSs) that are considered less technique sensitive and less time consuming, ${ }^{2,3,4,5}$ but are usually based on complex hydrophilic monomers that determine higher permeability ${ }^{6,7}$ and consequently more rapid degradation in the oral environment. ${ }^{8}$

For better adhesion to dentin, some authors have suggested the use of lasers for dentin conditioning, as laser irradiation can provide an apparently microretentive surface, free of a smear layer and open dentinal tubules. ${ }^{910}$ However, despite this notable morphology, laser-treated dentin has been reported to provide bond strength values only equal to or lower than those of dentin treated in the traditional manner. ${ }^{11,12}$

Recently, a different approach was suggested to promote better adhesion to dentin via lasers. Gonçalves et al..$^{13}$ proposed the laser irradiation of already infiltrated dentin adhesive systems, prior to their polymerization. This technique promoted increased bond strength values of simpli-
Submitted: Mar 28, 2014

Accepted for publication: Jul 15, 2014

Last revision: Oct 13, 2014 
fied DBSs irradiated with the Nd:YAG laser in microtensile ${ }^{14}$ and shear bond strength tests..$^{15}$ According to those authors, laser irradiation could increase bond strength by determining a higher penetration of DBSs into dentin ${ }^{14}$ or promoting the development of a substrate where dentin and adhesive are fused by the action of the laser. ${ }^{15}$

As an alternative, the diode laser also provides a near-infrared irradiation (wavelength $=970 \mathrm{~nm}$ ) with parameters similar to those provided by Nd:YAG, but with more attractive usage and availability, such as lower size, weight, and cost. Because the influence of diode laser irradiation associated with simplified DBSs has not been well established, the aim of this study was to evaluate, through the microtensile bond strength test, the effect of diode laser irradiation on two simplified DBSs applied to human dentin.

The null hypothesis is that laser irradiation may not determine different bond strength values to dentin with simplified DBSs.

\section{Methodology Experimental Design}

This was a factorial $2 \times 2$ in vitro study wherein the factors were two adhesive systems [(SB) Adper ${ }^{\mathrm{TM}}$ SingleBond 2, 3M ESPE, St. Paul, USA; and (EO) AdperTM EasyOne, 3M ESPE, St. Paul, USA] with two levels of laser irradiation [CONTROL, no irradiation; (L) LASER, irradiation with a diode laser, SiroLaser, Sirona, Bensheim, Germany].

The experimental sample consisted of 40 teeth, randomized by crown size and assigned to one of the above four groups $(n=10)$. The quantitative response variable was bond strength to dentin in megaPascals (MPa), obtained from microtensile specimens tested for each tooth.

\section{Sample Preparation}

Forty sound human third molars (Figure 1A) indicated for extraction were obtained from the dental emergency clinic of Bauru School of Dentistry, Universidade de São Paulo - USP, after approval by the Ethics Committee of Research on Human Beings at the same institution (CAAE 05737812.7.0000.5417). Immediately after extraction, the teeth were cleaned with periodontal curettes and stored in a $0.1 \%$ thymol solution (ISO TR 11405), renewed weekly. They were kept immersed until the specimens were prepared.

Each selected tooth had its crown sectioned transversely on the occlusal third by means of a sectioning machine (Figure 1B) (Isomet ${ }^{\mathrm{TM}}$ Low Speed Saw ${ }^{\circledR}$, Buehler, Lake Bluff, USA) with a water-cooled diamond disc (Extec Corporation, Enfield, USA) to expose superficial dentin for adhesive procedures, after which it was subjected to wear on a polishing machine (Figure 1C) (Arotec, Cotia, Brazil) with 320-grit silicon carbide paper (Carbimet Paper Discs, Buehler) for the eventual removal of enamel remaining on the surface. The teeth were then polished for $30 \mathrm{~s}$ with a 600-grit $\mathrm{SiC}$ paper to simulate smear layer formation.

Over the flat dentin (Figure 1D), a $6 \mathrm{~mm} \times 6 \mathrm{~mm}$ condensation-cured silicon mold (Zetalabor, Zhermack, São Paulo, Brazil) was positioned centrally in each specimen, and nail varnish was applied all around to delimit the testing area (Figure 1E), after which each group received the respective treatment according to the manufacturer's instructions (Table 1, Figures $1 \mathrm{~F}$ and $1 \mathrm{G}$ ) followed by gentle air-drying for $10 \mathrm{~s}$ for solvent evaporation.

In the laser groups, after application of the dentin bonding system, a diode laser (Figure $1 \mathrm{H}$ ) was activated in contact mode, and the full testing area was scanned for $30 \mathrm{~s}$ with the tip perpendicular to

Table 1. Application technique for each dentin bonding system according to its manufacturer's instructions.

\begin{tabular}{|c|c|}
\hline Adhesive system & Application technique \\
\hline $\begin{array}{l}\text { Adper }^{\top M} \text { Single Bond } 2 \\
3 M \text { ESPE, St. Paul, MN, USA }\end{array}$ & $\begin{array}{c}\text { Etch dentin surface with phosphoric acid (37\%) for } 15 \mathrm{~s} \\
\text { Rinse for } 15 \mathrm{~s} \\
\text { Gently dry with absorbent paper } \\
\text { Apply adhesive with a microbrush } \\
\text { Gently air-dry for } 10 \mathrm{~s}\end{array}$ \\
\hline $\begin{array}{l}\text { Adper }^{T M} \text { EasyOne } \\
\text { 3M ESPE, St. Paul, MN, USA }\end{array}$ & $\begin{array}{l}\text { Apply adhesive over a clean and dry dentin surface and wait for } 20 \mathrm{~s} \\
\text { Gently air-dry for } 10 \mathrm{~s}\end{array}$ \\
\hline
\end{tabular}




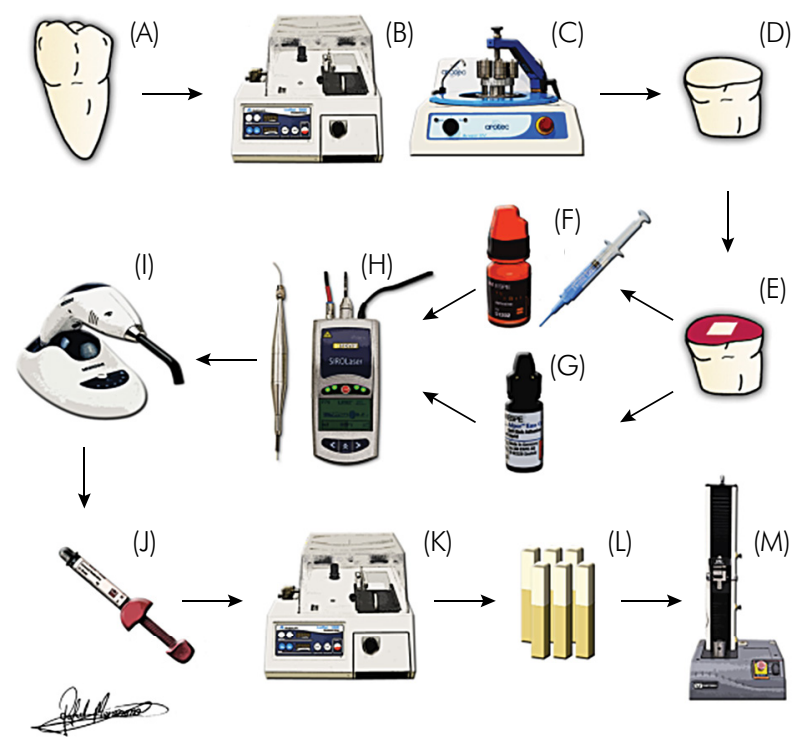

Figure 1. (A) Human third molar; (B) Sectioning machine; (C) Polishing machine; (D) Cut and polished specimen; (E) Specimen with delimited testing area; (F) Two-step etch-and-rinse adhesive system; $(G)$ One-step self-etch adhesive system; $(H)$ Diode laser; (I) Light-emitting diode; (J) Microhybrid composite resin; (K) Sectioning machine; (L) Beam-shaped stick specimens; (M) Universal testing machine.

the specimen's surface. Prior to laser application, the operator was trained to standardize the scanning speed, ensuring that the entire testing area was equally irradiated. Other parameters used for laser irradiation are listed in Table 2.

After laser irradiation, the specimens were lightcured for $20 \mathrm{~s}$ with light-emitting diodes (LED) (Blue Star 2, Microdont, São Paulo, Brazil) (Figure 1I) with $1 \mathrm{~W} / \mathrm{cm}^{2}$ power density positioned perpendicular to the dentin surface as closely as possible. Composite

Table 2. Diode laser parameters used for irradiation of the testing areas.

\begin{tabular}{lc}
\hline Parameter & Value \\
\hline Energy per pulse & $80 \mathrm{~mJ}$ \\
Frequency & $10 \mathrm{~Hz}$ \\
Power & $0.8 \mathrm{~W}$ \\
Testing area & $36 \mathrm{~mm}^{2}$ \\
Irradiation time & $30 \mathrm{~s}$ \\
Total energy & $24 \mathrm{~J}$ \\
\hline
\end{tabular}

resin (Filtek ${ }^{\mathrm{TM}}$ Z250, 3M ESPE) (Figure 1J) was then applied with the incremental technique with three consecutive $1.5-\mathrm{mm}$ thick increments, each also lightcured for $20 \mathrm{~s}$. Specimens were immersed in deionized water at $37^{\circ} \mathrm{C}$ for 7 days.

After storage, specimens were sectioned (Figure 1K) perpendicular to the bonding surface to create multiple beam-shaped sticks with a cross-sectional surface area of approximately $1.0 \mathrm{~mm}^{2}$ (Figure 1L).

\section{Microtensile test}

Prior to being tested, the cross-sectional area of each specimen's adhesive interface was measured with a digital caliper (Digimatic Caliper, Mitutoyo Sul Americana, Rio de Janeiro, Brazil), and the values were entered into the BlueHill Lite software (BlueHill ${ }^{\circledR}$ Materials Testing Software, Norwood, USA). Specimens were then attached individually with a cyanoacrylate-based adhesive (Loctite Super Bonder Gel Control, Henkel Ltda, São Paulo, Brazil) to a microtensile dispositive similar to Bencor Multi T (Danville Engineering, San Ramon, USA) adapted to a universal testing machine (Figure 1M) (Instron 3342, Illinois Tool Works, Norwood, USA). The specimen's adhesive interface was positioned perpendicular to the tensile forces generated by the testing machine. Testing was performed at $0.5 \mathrm{~mm} / \mathrm{min}$ speed (ISO TR 11405) with a $500 \mathrm{~N}$ load cell. Bond strength values $(\mathrm{MPa})$ were calculated on the basis of the maximum force supported by each specimen (in N) divided by the cross-sectional area ratio of each specimen (in $\mathrm{mm}^{2}$ ).

\section{Failure mode analysis}

After being tested, both segments of the fractured specimens were analyzed with a digital portable microscope (Dino Lite Microscope 100×, AnMo Electronics Corp, New Taipei City, Taiwan) and classified by failure modes: Adhesive (A) for failures at the adhesive interface; Cohesive in Dentin (CD) for failures on the dentin substrate; Cohesive in Resin (CR) for failures in the resin composite; and Mixed (M) when none of the types predominated. The percentage of each type of failure was obtained. 
Table 3. Microtensile bond strength of dentin bonding systems with or without irradiation using a diode laser [Mean $(\mathrm{MPa}) \pm$ standard deviations].

\begin{tabular}{lcc}
\hline Adhesive System & Control & Diode Laser \\
\hline SB & $33.49 \pm 6.77 \mathrm{Aa}$ & $43.69 \pm 8.15 \mathrm{Ba}$ \\
$\mathrm{EO}$ & $19.67 \pm 5.86 \mathrm{Ab}$ & $29.87 \pm 6.98 \mathrm{Bb}$ \\
\hline
\end{tabular}

$N=10$

Uppercase letters represent differences between columns $(p=0.012)$.

Lowercase letters represent differences between rows $(p<0.001)$.

\section{Statistical analysis}

Data were subjected to two-way ANOVA $(p \leq 0.05)$ followed by Tukey's test $(p<0.05)$ for individual comparisons. Statistical analysis was performed with the software Statistica 10.0 (StatSoft, Inc., Tulsa, USA).

\section{Results}

Both factors (DBSs and laser) were significant by two-way ANOVA. For the adhesive factor, higher bond strength values were obtained when the etch-andrinse adhesive system (SB) was used. For the laser factor, both groups (SB-L and EO-L) yielded higher bond strength values (Table 3). Adhesive failures were predominant in all groups. The distribution of each type of failure mode is described in Table 4.

\section{Discussion}

Results obtained in this in vitro evaluation showed an increase in bond strength in both adhesive systems when the diode laser was irradiated, rejecting the null hypothesis. Similar results have already been reported with the Nd:YAG laser irradiation of simplified DBSs, ${ }^{14,15}$ suggesting that near-infrared laser irradiation is a promising technique for achieving a more reliable link to dentin; however, the underlying mechanism is still unknown.

Some authors have speculated that laser irradiation promotes "the development of a new substrate, in which dentin substrate and adhesive would be fused

Table 4. Failure mode distribution (\%) for each group.

\begin{tabular}{lcccc}
\hline & $\mathrm{A}$ & $\mathrm{CR}$ & $\mathrm{CD}$ & $\mathrm{M}$ \\
\hline SB & $94 \%$ & $3 \%$ & $3 \%$ & $0 \%$ \\
EO & $76 \%$ & $3 \%$ & $0 \%$ & $21 \%$ \\
SB-L & $65 \%$ & $25 \%$ & $5 \%$ & $5 \%$ \\
EO-L & $96 \%$ & $0 \%$ & $0 \%$ & $4 \%$ \\
\hline
\end{tabular}

(A) Adhesive; (CR) Cohesive in Resin; (CD) Cohesive in Dentin; (M) Mixed. by laser action,"15 thus obtaining higher bond strength values. As hydroxyapatite melting occurs only at a very high temperature (approximately $800^{\circ} \mathrm{C}$ ), ${ }^{16}$ the intra-pulp-chamber temperature is another issue that must be investigated.

Another attempt to explain the immediate increase in bond strength is the heat provided directly by laser irradiation, which could favor adhesive penetration ${ }^{14}$ and solvent evaporation. It was recently found that a warm air stream can also provide immediate increases in bond strength values of simplified DBSs,${ }^{17}$ which could also explain the favorable results obtained with the laser irradiation technique.

The pronounced but local heat generation caused by laser irradiation may also determine a higher degree of conversion of the adhesives already infiltrating the dentin, especially if the diode laser wavelength is well absorbed by the adhesives. Fourier transform infrared spectrometry and near-infrared spectrometry may be notable instruments for these evaluations.

Despite the favorable results, the immediate increase in bond strength does not guarantee that the resin composite restorations with margins in dentin will last longer, especially in posterior tooth restorations, because the main cause of failures is the degradation of the hybrid layer over time. ${ }^{1}$ Conversely, the immediate increase in bond strength reveals that some favorable interaction is proceeding, which must stimulate more investigations in this field.

Laser irradiation may represent one more step in dentin hybridization; however, the results provide evidence that simplified DBSs can also establish high bond strength values to dentin. Other studies should be performed to investigate the underlying mechanism by which laser irradiation can promote increased bond strength values and also the longevity of the laser-treated hybrid layer after water storage and before clinical usage.

\section{Conclusion}

Based on the results of this study, the association of diode laser irradiation with simplified adhesive systems already applied to dentin, but prior to polymerization, is a promising alternative for achieving higher bond strength values. 


\section{Acknowledgments}

This manuscript is part of a dissertation submitted by the first author to the Bauru School of Dentistry, Universidade de São Paulo - USP, in partial ful-

\section{References}

1. Spencer P, Ye Q, Park J, Topp EM, Misra A, Marangos O, et al. Adhesive/Dentin interface: the weak link in the composite restoration. Ann Biomed Eng. 2010 Jun;38(6):1989-2003.

2. Tay FR, Gwinnett JA, Wei SH. Micromorphological spectrum from overdrying to overwetting acid-conditioned dentin in water-free acetone-based, single-bottle primer/adhesives. Dent Mater. 1996 Jul;12(4):236-44.

3. Pashley DH, Carvalho RM, Sano H, Nakajima M, Yoshiyama M, Shono Y, et al.. The microtensile bond test: a review. J Adhes Dent. 1999 Winter;1(4):299-309.

4. Melo MA, Goes DC, Moraes MD, Santiago SL, Rodrigues LK. Effect of chlorhexidine on the bond strength of a self-etch adhesive system to sound and demineralized dentin. Braz Oral Res. 2013 May-Jun;27(3):218-24.

5. Sánchez-Ayala A, Farias-Neto A, Vilanova LS, Gomes JC, Gomes OM. Marginal microleakage of class V resin-based composite restorations bonded with six one-step self-etch systems. Braz Oral Res. 2013 May-Jun;27(3):225-30.

6. Tay FR, Pashley DH, Suh BI, Carvalho RM, Itthagarun A. Single-step adhesives are permeable membranes. J Dent. 2002 Sep-Nov;30(7-8):371-82.

7. Tay FR, Pashley DH, Yoshiyama M. Two modes of nanoleakage expression in single-step adhesives. J Dent Res. 2002 Jul;81(7):472-6.

8. De Munck J, Van Landuyt K, Peumans M, Poitevin A, Lambrechts $\mathrm{P}$, Braem $\mathrm{M}$, et al. A critical review of the durability of adhesion to tooth tissue: methods and results. J Dent Res. 2005 Feb;84(2):118-32.

9. Visuri SR, Gilbert JL, Wright DD, Wigdor HA, Walsh JT Jr. Shear strength of composite bonded to Er:YAG laser-prepared dentin. J Dent Res. 1996 Jan;75(1):599-605. fillment of the requirements for the Master's degree in Restorative Dentistry. This study was supported by Conselho Nacional de Desenvolvimento Científico e Tecnológico - CNPq (Process \#134356/2011-0).

10. Dostálová T, Jelínková H, Kucerová H, Krejsa O, Hamal K, Kubelka J, et al. Noncontact Er:YAG laser ablation: clinical evaluation. J Clin Laser Med Surg. 1998 Oct;16(5):273-82.

11. De Munck J, Van Meerbeek B, Yudhira R, Lambrechts P, Vanherle G. Micro-tensile bond strength of two adhesives to Erbium:YAG-lased vs. bur-cut enamel and dentin. Eur J Oral Sci. 2002 Aug;110(4):322-9.

12. Oliveira MT, Reis AF, Arrais CAG, Cavalcanti AN, Aranha AC, de Paula Eduardo C, Giannini M. Analysis of the interfacial micromorphology and bond strength of adhesive systems to Er:YAG laser-irradiated dentin. Lasers Med Sci. 2013 Jul;28(4):1069-76.

13. Gonçalves SEP, Araujo MAM, Damiao AJ. Dentin bond strength: influence of laser irradiation, acid etching, and hypermineralization. J Clin Laser Med Surg. 1999 Apr;17(2):77-85.

14. Franke M, Taylor AW, Lago A, Fredel MC. Influence of Nd:YAG laser irradiation on an adhesive restorative procedure. Oper Dent. 2006 Sep-Oct;31(5):604-9.

15. Marimoto AK, Cunha LA, Yui KC, Huhtala MF, Barcellos DC, Prakki A, et al. Influence of Nd:YAG Laser on the Bond Strength of Self-etching and Conventional Adhesive Systems to Dental Hard Tissues. Oper Dent. 2013 Jul-Aug;38(4):447-55.

16. Zuerlein MJ, Fried D, Featherstone JDB. Modeling the modification depth of carbon dioxide laser-treated dental enamel. Lasers Surg Med. 1999 25(4):335-47.

17. Reis A, Wambier L, Malaquias T, Wambier DS, Loguercio AD. Effects of warm air drying on water sorption, solubility, and adhesive strength of simplified etch-and-rinse adhesives. J Adhes Dent. 2013 Feb;15(1):41-6. 